\title{
Zola en Europe centrale, études réunies par Norbert Bachleitner, Tone Smolej \& Karl Zieger
}

\section{Maria Emanuela Raffi}

\section{(2) OpenEdition}

1 Journals

\section{Edizione digitale}

URL: http://journals.openedition.org/studifrancesi/3825

DOI: $10.4000 /$ studifrancesi.3825

ISSN: 2421-5856

\section{Editore}

Rosenberg \& Sellier

\section{Edizione cartacea}

Data di pubblicazione: 1 décembre 2012

Paginazione: 602

ISSN: 0039-2944

\section{Notizia bibliografica digitale}

Maria Emanuela Raffi, «Zola en Europe centrale, études réunies par Norbert Bachleitner, Tone Smolej \& Karl Zieger», Studi Francesi [Online], 168 (LVI | III) | 2012, online dal 30 novembre 2015, consultato il 08 mars 2021. URL: http://journals.openedition.org/studifrancesi/3825 ; DOI: https://doi.org/10.4000/ studifrancesi.3825

Questo documento è stato generato automaticamente il 8 mars 2021.

\section{(c) (1)}

Studi Francesi è distribuita con Licenza Creative Commons Attribuzione - Non commerciale - Non opere derivate 4.0 Internazionale. 


\title{
Zola en Europe centrale, études réunies par Norbert Bachleitner, Tone Smolej \& Karl Zieger
}

\author{
Maria Emanuela Raffi
}

\section{NOTIZIA}

AA. VV., Zola en Europe centrale, études réunies par Norbert BACHLEITNER, Tone SMOLEJ \& Karl ZIEGER, Presses Universitaires de Valenciennes, 2011, pp. 314.

1 La pubblicazione si propone di fare luce sulla diffusione e la conoscenza dell'opera di Zola nei paesi dell'Europa centro-orientale, nelle diverse forme di diffusione in lingua originale, di traduzioni, di riflessione critica e di adattamenti teatrali, come precisano $\mathrm{i}$ curatori nella «Préface».

Yves CHEVREL si interroga nel suo studio Réceptions européennes de Zola (1870-1914: quelques éléments d'un dossier complexe) su quali siano le vie percorse dalla ricezione di Zola in Europa e soprattutto sulla mediazione rappresentata dal naturalismo, ben accolto nei paesi dell'Europa occidentale, ma anche in Russia e, a partire dal 1880, anche nei paesi dell'Europa centrale. L'A. pone anche il problema anche di ciò che è stato tradotto dell'autore francese nei vari paesi e dell'immagine di Zola che vi ha circolato, diversa secondo la storia letteraria del paese e i contatti con i vari autori contemporanei. Negli undici articoli che seguono vengono illustrate le diverse situazioni di diffusione e conoscenza dell'opera zoliana nei differenti paesi dell'Europa centrale: N. BACHLEITNER, Vienne, lieu de réception de Zola: traduction, critique, médiation en Europe centrale; A. BARJONET, Une version abrégée et érotique des "Rougon-Macquart" "made in Budapest»; J. RACHWALSKA VON REJCHWALD, Apologie et aversion. La réception de Zola en Pologne; N. TSIKRA-ST. SIMONEK, La réception d'Émile Zola dans les périodiques de Lwow/L'viv (Lemberg) vers 1900; J. SOTOLOVA, Émile Zola et la Tchèque; J. TRUHLÁROVÁ, Émile Zola et le «naturalisme» slovaque; S. KÁLAI, La réception de Zola en Hongrie; T. SMOLEJ, La réception d'Émile Zola chez les Slovènes à 
l'époque de l'Autriche-Hongrie; FL. GACOIN-MARKS, Eugen Kumic'ic' et la première réception d'Émile Zola en Croatie; J. NOVAKOVIC, La réception de Zola en Serbie (1881-1914); K. ZIEGER, Alfred Dreyfus et Émile Zola, protagonistes de représentations populaires de l'Affaire. In quest'ultimo articolo sono prese in esame due opere teatrali sull'«affaire Dreyfus» rappresentate rispettivamente a Berlino e a Vienna nel 1929 e nel 1930.

Un bibliografia molto ricca delle traduzioni, degli articoli critici e degli spettacoli relativi all'opera di Zola, organizzata in ordine cronologico dal 1873 al 1918, completa il volume. 